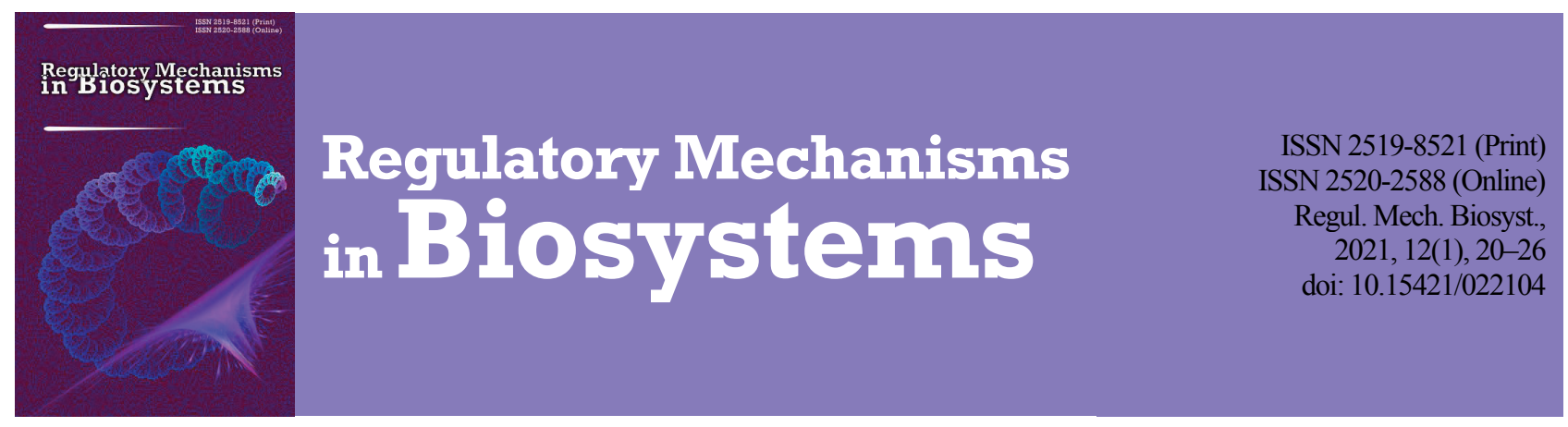

\title{
Effect of immunological castration of male pigs on morphological and functional condition of the testicles
}

\author{
V. V. Samoiliuk*, M. S. Koziy**, D. D. Bilyi*, S. M. Maslikov*, T. L. Spitsina*, L. I. Galuzina* \\ *Dnipro State Agrarian and Economic University, Dnipro, Ukraine \\ **Petro Mohyla Black Sea National University, Mykolayiv, Ukraine
}

Article info

Received 12.01.2021

Received in revised form 17.02.2021

Accepted 18.02.202

Dnipro State Agrarian and Economic University, Efremov st., 25, Dnipro, 49600, Ukraine. Tel.: +38-066-221-69-47. E-mail:

samoluk1966@ukr.net

Petro Mohyla Black Sea National University,

Desantnykiv st., 10,

Mykolayiv, 54000,

Ukraine.

Tel.: + 38-051-250-03-33.

E-mail:

Mykhaylo.Koziy

@) chmти.edu.ue
Samoiliuk, V. V., Koziy, M. S., Bilyi, D. D., Maslikov, S. M., Spitsina, T. L., \& Galuzina, L. I. (2021). Effect of immunological castration of male pigs on morphological and functional condition of the testicles. Regulatory Mechanisms in Biosystems, 12(1), 20-26. doi:10.15421/022104

Changes in the priorities of the treatment of animals in the conditions of intense technology of production of livestock products are based on the necessity of wellbeing of animals. Therefore, there is a need of search for and broad introduction of generally accepted alternatives to surgery, which would use modern means of castration, particularly immunocastration. The study presents morpho-functional substantiation of practicability of using immunological castration in the conditions of industrial production of pork. At the same time, we studied immunological castration using Improvak on the morphological and physiological condition of the testicles of male pigs. The testosterone level was determined using radioimmunologic method after 2, 4, 6, 8 weeks of immunological and surgical castrations, and also in intact boars of the control group. During the slaughter, we selected biopates of the testicles in immunological castrates and pigs of the control group for histological examination. The testosterone level 2 weeks after castration was the lowest in the animals castrated using Improvak. This indicator gradually increased, and after 8 weeks was higher than in the surgically castrated pigs. In the latter, the level of testosterone gradually decreased for 8 weeks, and did not significantly change in non-castrated pigs. The last stages of spermatogenesis in immunocastrates were inhibited after the second vaccination. As a result of immunological castration, the interstitial tissue of the testicle underwent changes. Between the tubules, a spreading of the loose connective tissue was observed. Leydig cells lost hyper chromaticity of the cytoplasm and typical polygonal profile, and their functional potential decreased. This fact was confirmed by the changes in the Hertwig's ratio. In particular, we observed decrease in the value of the nuclear-cytoplasmic ratio. There were also a time shift of mitotic cycle, low degree of differentiation of spermatogonia and rupture of the course of the subsequent stages of spermatogenesis. However, there occurred multiplication of primary spermatogonia, single cellular divisions, and in the ductus deferentes, there could be found single spermatids. Some of them formed specific cellular groups of rounded and elliptic shapes in the seminiferous tubules. These structures were absent in the testicles of the control animals. Microstructural changes in the swine after injecting Improvak were characterized by deficiency of Leydig cells, indicating absence of the normal hormonal background, as confirmed by the results of the study of testosterone level. The epithelium-spermatogenic layer was underdeveloped, and the lumens of the tubules were in some places filled with generations of spermatocytes. In some places, meiosis was observed, which also indicates insignificant functioning of the testicles. Vaccination with Improvak caused atrophy of the testicles in swine and decrease in their functional condition, allowing it to be recommended it for broader application as an alternative to surgical castration.

\section{Introduction}

On pig farms in many countries, to regulate aggressive and sexual behaviour of boars and prevent development of unpleasant smell of pork, surgical castration is performed regularly (Bradford \& Mellencamp, 2013). However, this painful procedure has a negative impact on the health of pigs (Aluwé et al., 2015), and according to some reports, pain in castrated piglets may be assessed according to the behavioural changes taking place before and after the procedure (Yuna et al., 2019). At the same time, surgical castration with anesthesia is negatively viewed by pork manufacturers from the perspective of the work conditions (Tuyttensa et al., 2012). Immunological castration is the most successful alternative to the surgical method (Zamaratskaia \& Rasmussen, 2015). Therefore, immunological castration of pigs during fattening using the vaccine against the chorionic gonadotropin releasing factor $(\mathrm{GnRF})$ is considered by the authors as a possible solution to the problems related to the surgical castration, which causes pain and stress even during local or general anesthesia (Baumgartner et al., 2010). Therefore, the interest in studying the efficieny of immunological castration and the mechanisms of its action on the organism has recently increased. Immunological castration of piglets is gradually displacing surgical castration. It includes two subsequent vaccinations for production of antibodies that temporarily inhibit the functions of the testicles. This method of provision of both high quality of the products and high level of welfare of the animals is still being currently thoroughly studied, for up to now there is no contemporary global analysis of various aspects of this problem (Kress et al., 2019).

Gonadotropin releasing factor is an essential regulator of the functions of the testicles and maturity of mammals. It is produced by the hypothalamus during sexual maturation. This factor associates with specific receptors of the hypophysis and stimulates release of follicle-stimulating and luteinizing hormones that intensify growth and activity of the testicles, leading to changes in the behaviour of the animal and unpleasant smell of the meat products (Zamaratskaia et al., 2008).

Despite the fact that immunological castration of pigs is the alternative method to the surgery, it is still viewed differently by the manufacturers and consumers of pork (Pasquale et al., 2019). As an alternative to surgery, immunological castration has its pros and cons (Bonneau \& Weiler, 2019). According to scientific reports, immunological castration 
affects morphometric parameters of the testicles in male pigs (Gogić et al., 2019), and other reproductive organs (Škrlep et al., 2012). Histological changes in the tubules and the interstitial tissue of the testicle are also objective parameters of successful castration. The mentioned changes include decrease in the diameter of the seminiferous tubules, amount of interstitial endocrine cells and embryonic epithelium (Brunius et al., 2011), as well as inhibition of spermatogenesis and decrease in the number of Leydig cells (Mitjana et al., 2020).

Contemporary studies indicate that prior vaccination leads to significant irreversible changes in the testicles. In particular, decrease in the testosterone level, decrease in the sizes of the testicles and the bulbourethral gland, and also inhibition of spermatogenesis were observed. These significant consequences are associated with drop in the level of testosterone and other hormones that are produced by the interstitial endocrine cells, the level of which is lower than needed for spermatogenesis (Sladek et al., 2018).

Testosterone not only supports the process of spermatogenesis, but protects the function of androgen-dependent tissues. Leydig cells are the main source of synthesis and secretion of testosterone in the testicles of mammals (Yu et al., 2017). However, the available scientific sources still contain insufficient data on the problems indicated above. Therefore, the study of the impact of immunocastration of male pigs on morphological and functional condition of the testicles is still a relevant problem. We aimed at assessing the morphological and functional changes in the testicles of male pigs that were castrated by the immunological vaccine Improvak.

\section{Materials and methods}

The studies were performed according to the requirements of the European Convention for the Protection of Vertebrate Animals used for. Experimental and Other Scientific Purposes (Strasburg, 1986) and the law of Ukraine "On protection of animals against abuse" (2006), which was confirmed by the Commission of Bioethics of the Dnipro State AgrarianEconomic University. To study the efficiency of the immunological castration of male pigs, we assessed its effect on functional and morphological conditions of the testicles. During the studies, the male pigs were divided into three groups, each comprising 10 animals (Table 1). The first group consisted of male pigs that underwent immunological castration by Improvak vaccine, the second - surgically castrated using open technique with hemorrhage-controlling ligature. The third group was composed of intact male pigs. Improvak was injected subcutaneously in the dose of 2 $\mathrm{mL}$ per animal with 4 weeks interval. The second injection was given 5 weeks before the slaughter.

At 2, 4, 6, 8 weeks after the immunological castration, we drew blood from the pigs to determine the testosterone level. The results of this test we then compared with those of the male pigs that had not been castrated and the ones castrated surgically. Testosterone level in blood serum was determined using radioimmunological analysis. The male pigs of all the groups were monitored so as to determine the impact the castration had on their behaviour, growth intensity and development of the testicles.

Table 1

Scheme of the experiment

\begin{tabular}{cc}
\hline Group of animals (male pigs) & Method of castration \\
\hline I & castrated immunologically \\
II & castrated surgically \\
III & non-castrated pigs \\
\hline
\end{tabular}

During the slaughter, we collected biopsy samples of the testicles of immunologically castrated animals to perform histological examinations in order to compare the condition of the testicles at the microstructural level with non-castrated pigs of the same age from which the material was collected by surgical castration.

The histological preparations were prepared using modified paraffincelluloid technique of M. S. Koziy. The preparations were viewed under the microscope and the peculiarities of the tissue of the testicles were analyzed in surgical and immunological castrates. At the same time, we paid special attention on Leydig cells (interstitial cells) located in the connective tissue between the ductus deferentes and Sertoli cells.
The obtained results were statistically analyzed in Statistica 10 software (StatSoft Inc., USA, 2011). To determine the likelihood of difference between the selections, we used ANOVA with Bonferroni correction.

\section{Results}

Two weeks after Improvak vaccination, testosterone level was 7.8 times lower than in non-castrated animals and 4.5 times lower compared with surgically castrated animals. Eight weeks later, in the immunological castrates, this parameter had increased (became 9.0 times higher than in surgically castrated pigs) and 4.4 lower compared with noncastrated ones.

\section{Table 2}

Dynamics of testosterone level in pigs depending on the castration teschnique ( $\mathrm{nmol} / \mathrm{L}, \mathrm{x} \pm \mathrm{SD}, \mathrm{n}=10$ )

\begin{tabular}{lcccc}
\hline \multirow{2}{*}{ Group of animals } & \multicolumn{4}{c}{ Period of the study } \\
\cline { 2 - 5 } & 2 weeks & 4 weeks & 6 weeks & 8 weeks \\
\hline Immunological & & & & \\
castrates & $0.59 \pm 0.16^{* * * *}$ & $0.87 \pm 0.36^{* * *}$ & $0.39 \pm 0.09^{* * *}$ & $1.09 \pm 0.01^{* * * *}$ \\
Surgical castrates & $2.77 \pm 0.12^{*}$ & $1.37 \pm 0.32^{* * *}$ & $0.77 \pm 0.12^{* * *}$ & $0.12 \pm 0.08^{* * *}$ \\
Non-castrated pigs & $4.65 \pm 0.47$ & $3.95 \pm 0.52$ & $4.00 \pm 0.37$ & $4.85 \pm 0.92$ \\
\hline
\end{tabular}

Note: * $-\mathrm{P}<0.05, * * \bullet-\mathrm{P}<0.01, * * *-\mathrm{P}<0.001$, compared non-castrated $(*)$ or surgically castrated pigs $(\bullet)$ according to the results of comparison with ANOVA application with Bonferroni correction.

Histological section of the testicle of a pig of the control group was first of all made transversally, at the level of its middle part (Fig. 1). Having analyzed the content of this figure, we can state that each ductus deferens was developed by its own connective tissue membrane laid by spermatogenic epithelium containing various generations of zonally oriented cells in the process of development. The space between the ductus deferentes was filled with the interstitial tissue containing arterioles and capillaries. In this tissue, groups of Leydig cells were clearly noticeable. The markedly acidophilous colour of the latter indicates active secretion of testosterone (Fig. 1a). It has to be noted that such an amount of them is characteristic of microstructural peculiarity of the pigs' testicles.

The detailed histological picture allowed us to determine the morphological peculiarities (Fig. 1b). The tubule's smooth muscle contains a certain amount of fibers, between which there are separate stretched fibrocyte nuclei. Epithelium of the seminiferous tubules is separated from their connective-tissue membrane by poorly noticeable basement membrane. The epithelium cells develop some sort of "Sertoli fund". Between them, there are spermatogenous cell generations that are distinct due to their variability, indicating phase pattern of the course of spermatogenesis. The observations reveal that Sertoli cells in swine are most often located right near the basement membrane, but sometimes they penetrate deeper and are located above the row of spermatogonia. The nuclei are often observed to be at large distances from one-another. They may be diagnosed according to large size, epithelial shape and well-noticeable nucleolus. The low amount of chromatine is responsible for their light colour. In general, cytoplasm of Sertoli cells is seen unclearly. Nonetheless, it is noticeable in the pernuclear space.

Some methods of selective staining allowed us to obtain an objective picture of the condition of spermatogenous cell generations (Fig 1c). The first cellular layer that develops sperm is composed of relatively small cells - spermatogonia. Around their rounded, markedly hyperchromatic nuclei, we observed narrow layers of cytoplasm. Spermatogonia were observed both in interkinesis and the process of division.

Deeper (closer to the tubule lumen), there was a layer of first-order spermatocytes. Visually, they are larger cells with a wide cytoplasmic belt around the nucleus. While they undergo meiosis cycle, within one tubule, the cells of this type occur in various conditions (Fig. 1d). This figure clearly demonstrates that when preparing for division, the nucleus may be identified according to absence of a noticeable nuclear envelope and tangled clusters of chromosomes. First-order spermatocytes that were undergoing the division were characterized by short chromosomes that develop a compact chromosome figure that occupies a large part of the total volume of the cell. Spermatocytes of the second order that were seen in the condition of interkinesis were different by somewhat greater size. 


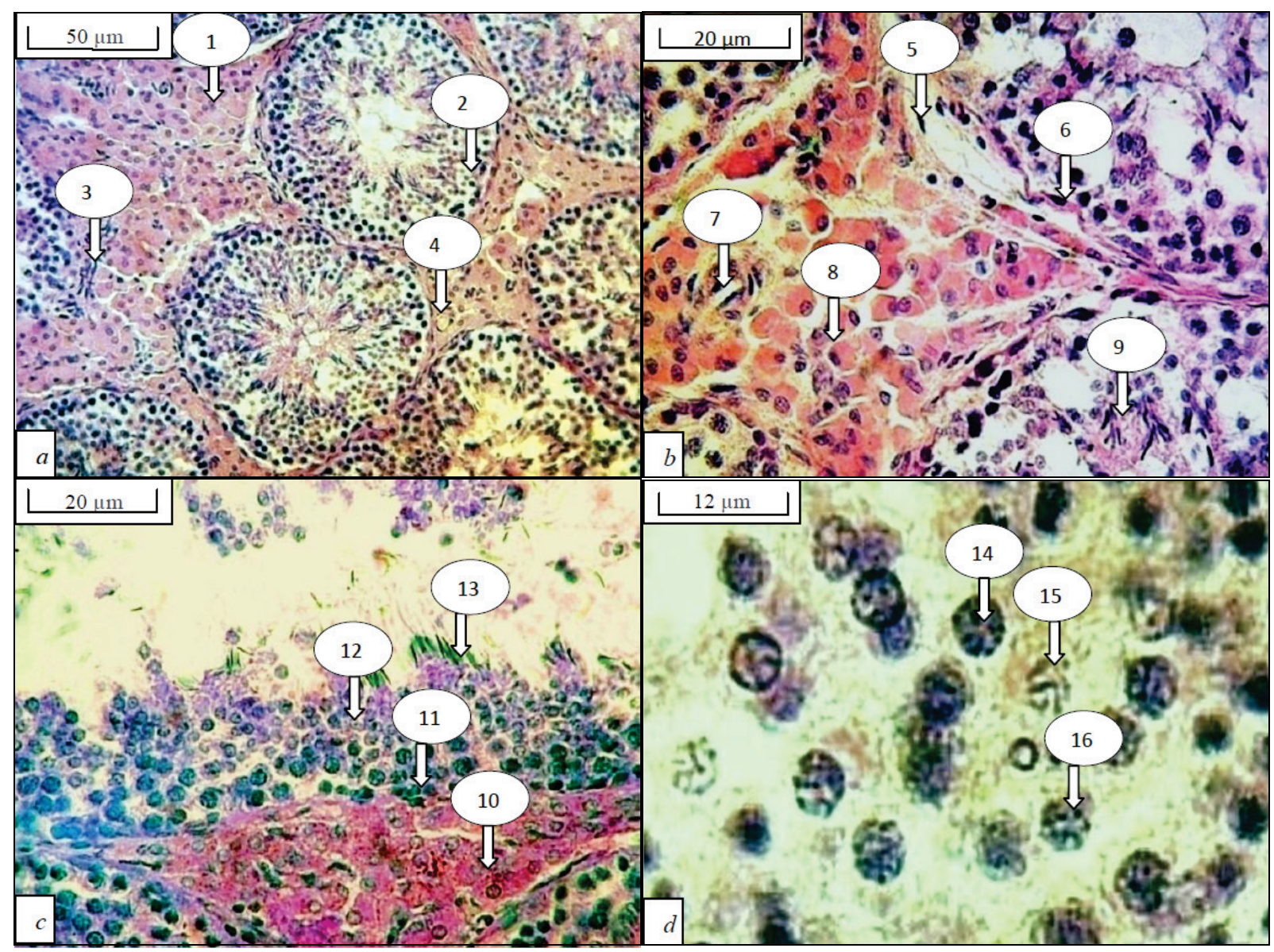

Fig. 1. Testicle of surgically castrated pig: $a$ - concentration of Leydig cells (1), spermatogenous cell generations (2), capillary (3), arteriole (4) (Bemer's hematoxylin, Hart's fuchselin (modified)); $b$ - structure of the interstitial and tubule tissue of the testicle of piglet castrated surgically: fibrocyte (5), Sertoli cell (6), arteriole (7), accumulation of Leydig cells (8), spermatogenous cell generations (9) (Bemer's hematoxylin, Hart's fuchselin (modified)); $c$ - cytoarchitectonics of the spermatogenous cell generations: accumulation of Leydig cells (10), spermatogonia (11), first-order spermatocytes (12), spermatids (13) (Tsinzerling reactive (modified)); $d$-different conditions of spermatocytes: spermatocyte of the second row (14), condition of preparation ffor the division (15), second-order spermatocyte (16) (Tsinzerling reactive (modified))

Spermatids developed as a result of division of spermatocytes of the second order comprise the inner layer in the ductus deferentes and are usually located in several loosely arranged rows (Fig. 2a). According to the data we obtained, they are the smallest cells with light nucleus in which no nucleolus was seen. Among this generation, there often occurred cells with stretched nuclei, from which the cytoplasm seemed to peel off. In some tubules, we observed developed spermatozoa the tails of which were oriented toward the structure's lumen (Fig 1c). It should be mentioned that in earlier histological sections, in each tubule, in general, there was seen a similar situation, whereas on the length-wise (sagittal) sections, we observed changes in different stages of spermatogenesis that took place along the tubules in wavy-like pattern.

The general-view histological preparation presents the testicle of the animals that underwent immunological sterilization (Fig. 2b). This figure clearly shows a large amount of ductus deferentes divided by the interstitial tissue, in which groups of Leydig cells and blood vessels of different caliber occur. On one hand, the morphological picture is identical to the normal structure of the pig's testicle. At the same time, detailed analysis of quite thin $(2.5 \mu \mathrm{m})$ histological sections allowed us to determine that the sterilization resulted in changes in some elements (Fig. 2c). On the mentioned figure, one can notice absence of the lumen in the tubules due to cellular masses that fill them. The tubules' epithelium is separated from the connective tissue by a notable basement membrane. In the basement cellular layer, there are clearly distinct primary spermatogonia that look like rounded cells with light cytoplasm and markedly hyperchromatic nuclei. As we see, nuclei of spermatogonia develop an entire row near the base of the tubules, which is to some extent similar to the histological picture in the testicle of a surgically castrated pig (Fig. 1c). At the same time, the borders of the cells are almost unnoticeable. No other generations are seen in the testicle in this figure. We may also note that the interstitial tissue of the immunologically castrated pig had signs of changes (Fig. 2c). First of all, in the spaces between the tubules, the loose connective tissue had spread, impairing some sort of compact character of the structure in general. Leydig cells lost hyperchromaticity of their cytoplasm and typical polygonal profile, observed in the animals castrated surgically (Fig. 1b). However, the most important diagnostic trait was change in the nuclearcytoplasmic ratio or Hertwig's ratio (Table 3 ).

\section{Table 3}

Changes in Hertwig's ratio as a result of immunocastration of the pigs

\begin{tabular}{|c|c|c|c|c|c|c|}
\hline \multirow[t]{2}{*}{ Group } & \multicolumn{2}{|c|}{$\begin{array}{c}\text { Linear sizes } \\
\text { of Leydig cells, } \mu \mathrm{m}\end{array}$} & \multicolumn{3}{|c|}{ Area $(\mathrm{S}), \mu \mathrm{m}^{2}$} & \multirow{2}{*}{$\begin{array}{l}\text { Nuclear- } \\
\text { cytoplas- } \\
\text { mic ratio }\end{array}$} \\
\hline & $\mathrm{A} \times \mathrm{B}_{\mathrm{cell}}$ & $\mathrm{A} \times \mathrm{B}_{\text {muclas }}$ & cell & nucleus & cytoplasm & \\
\hline & $7.3 \pm 0.03 \times$ & $2.9 \pm 0.01 \mathrm{x}$ & 47.72 & 7.25 & 40.47 & 0.18 \\
\hline ontrol & $6.4 \pm 0.06$ & $2.5 \pm 0.02$ & \pm 2.23 & \pm 1.05 & \pm 1.97 & \pm 0.01 \\
\hline $\begin{array}{l}\text { Experi- } \\
\text { mental }\end{array}$ & $\begin{array}{c}6.4 \pm 0.05 \mathrm{x} \\
6.3 \pm 0.04\end{array}$ & $\begin{array}{c}2.0 \pm 0.02 \times \\
2.1 \pm 0.01\end{array}$ & $\begin{array}{c}38.14 \\
\pm 2.12^{*}\end{array}$ & $\begin{array}{c}3.80 \\
\pm 0.73 \text { ** }\end{array}$ & $\begin{array}{c}34.34 \\
\pm 1.83 *\end{array}$ & $\begin{array}{c}0.11 \\
\pm 0.01 * *\end{array}$ \\
\hline
\end{tabular}

Note: $*-\mathrm{P}<0.05, * *-\mathrm{P}<0.01$ compared with the parameters of the control group.

It is demonstrated that in the conditions of the experiment, cytoarchitecture of spermatogenous generations in some tubules may have a specific pattern (Fig. 2d). The figure clearly demonstrates spermatogonia chaotically filling the tubule. This fact indicates shift in the time of the mitotic cycle, determining the low degree of their differentiation and further stop in the course of the subsequent stages of spermatogenesis.

It has to be noted that during the recorded changes at the microscopic level of the structure of the testicles, in some tubules, the primary spermatogonia were nonetheless multiplying. This fact is confirmed by presence of single cellular divisions and therefore further development of spermato- 
cytes. The latter were observed in high numbers, in the center of the ductus deferentes. Further, in the conditions of the general chaotic condition of the cellular masses, in the ductus deferentes, one may see separate rodshaped nuclei of spermatids (Fig. 3a). As we see in the presented figure, there was no such picture as spermatids arranged "in a row" in this case.
Comparing it to the data of Table 3, we may state that decrease in the linear parameters of the cellular components ( $\mathrm{S}$ of cell, nucleus and cytoplasm $-1.26,1.92$ and 1.18 times) is the reason for decrease in the value of nuclear-cytoplasmic ratio (1.64 times respectively), which clearly confirms the decrease in the functional potential of Leydig cells.

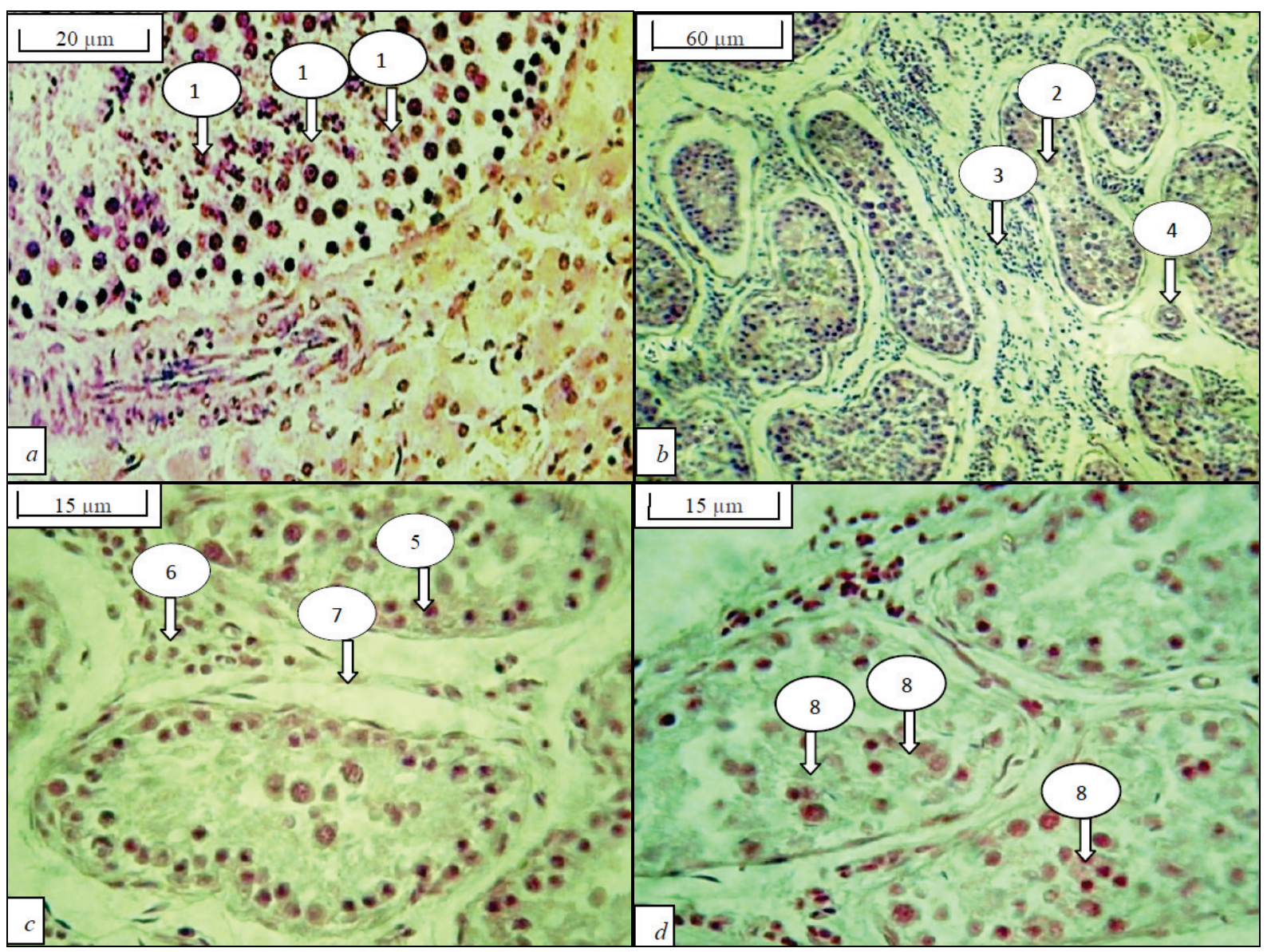

Fig. 2. Testicle of surgically castrated pig: $a$-spermatids ( 1 (Bemer's hematoxylin, Hart's fuchselin (modified)); testicle of pig castrated immunologically: $b$-spermatogenous tissue of the ductus deferens (2), the interstitial tissue (3), arteriole (4) (Bemer's hematoxylin, Hart's fuchselin (modified)); $c$-changes in the interstitial tissue and the ducti deferens of pig after immunological castration: initial spermatogonia (5), Leydig cells with reduced volume (6), swollen undeveloped connective tissue (7) (Bemer's hematoxylin, Hart's fuchselin (modified)); $d$ - damaged cytoarchitectonics of spermatogenous cells as a result of immunologic castration (8) (Bemer's hematoxylin, Hart's fuchselin (modified))

During the studies of the ductus derentes of the testicles of the animals of the experimental group, we found that some spermatocytes tended to form specific cellular groups (Fig. 3b, 3c, 3d). According to the results of light optic surveys, the observed structures had a ball-like or slightly elliptical shape, resembling syncytium. It has to be noted that their localization was characteristic exclusively of those tubules where spermatids occurred. The nuclei inside the tubules are always located on the periphery of cell. Within a separate structure, nuclei sometimes were of one or two types. In the first case, they were markedly hyperchromatic (oxyphilous), corresponding to first-order spermatocytes of the, and in the second case - near the nuclei of the first type, transparent vesicular nuclei were observed, which is characteristic of spermatocytes of the second order. It would be logical to consider the presence of two types within one formation of nuclei the result of local development of spermatocytes without their further differentiation. It should be pointed out that such a kind of structure was not seen in the testicles of surgically castrated animals and, according to the available literature, are currently completely unstudied.

Thus, during the analysis of histological preparations prepared from the testicles of pigs castrated with Improvakom, we determined that the late stages of spermatogenesis in the immunological castrates were inhibited. In the testicles of immunologically castrated pigs, which were extracted during the slaughter, we found notable deficiency of Leydig cells, indicating absence of the normal hormonal background. This fact is confirmed by the results of the surveys of the testosterone level (Table 2).
The epithelium-spermatogenic layer had been underdeveloped, causing malfunctioning in spermatogenesis that ended with spermatocytes. The lumens of the tubules were in some places filled with the generations of cells of this particular type. In some places, we also observed absence of the "reserve fund" of spermatogonia. At the same time, in some places, there locally occurred meiosis, suggesting insignificant but nonetheless functioning of the organ. Immunological castration inhibited the functional ability of Leydig and Sertoli cells. The mechanism of its action needs further studies.

\section{Discussion}

An important parameter that characterizes the functional condition of the testicles is the level of testosterone, and also the condition of spermatogenesis. It should be noted that three forms of this hormone are distinguished: inactive form, hormone bond with albumin (active bioavailable form), and free form that is most biologically available. Testosterone in the organism is produced by Leydig cells (interstitial cells), located in the connective tissue between the ductus deferentes. Sertoli cells that form the basal membrane of the seminiferous tubules develop a nutritional medium necessary for the differentiation and maturation of the sex cells. Therefore, during our studies, we paid special attention particularly to identifying the effect of Improval vaccine on the functional ability of those cells. The results we obtained to a large degree add to and confirm the data of another 
histological examination (Hilbe et al., 2006) and also comparisons between the testicles of male pigs castrated using Improvak vaccine and those castrated surgically. Similarly to the results of our study, the histological examination of the tissue of the testicles revealed clear signs of atrophy. Their weight decreased. The average diameter of the seminiferous tubules significantly decreased microscopically, and few spermatogonia and several spermatocytes were observed between the Sertoli cells. Leydig cells were seen to undergo atrophy.

Similarly to our experiment, other researchers determined the testosterone concentration in blood serum using radioimmunological analysis (Fang et al., 2010). The results revealed that the immunological castration was followed by decrease in the serum concentration of testosterone compared with the control. During the histological examination of the testicles, no mature spermatozoa were observed, which is coherent with our results.

The data we obtained are consistent with the reports by the authors indicating that immunization with Improvak affects the number and morphology of the Leydig interstitial cells. At the same time, spermatogenesis is affected to various degrees: from light damage (loss of spermatocytes, decrease in the normal number of the layers of sex cells) to severe loss of sex cells, including the tubules with Sertoli cells (complete vanishing of cellular embryo). In the epididymis, no or only few spermatozoa were observed. Similarly to our case, the immunological castration inhibited the synthesis of steroids in the testicles. The researchers think that the second vaccination should be carried out as later as possible to support the anabolic action of the testicles' hormones, but too early to remove androsterone from the fat of the organism (Claus et al., 2007).

As for the histological examinations of testicles of pigs vaccinated with Improvak, results similar to ours were also obtained by other researchers who also report significant inhibition of spermatogenesis in the testicles' seminiferous tubules, decrease in their diameter and the area and atrophy of the nuclei of the interstitial endocrine cells. Our studies confirm and add to the results of these authors indicating that castration with Improvak impairs spermatogenesis and decreases the number and sizes of interstitial endocrine cells (Sladek et al., 2018).

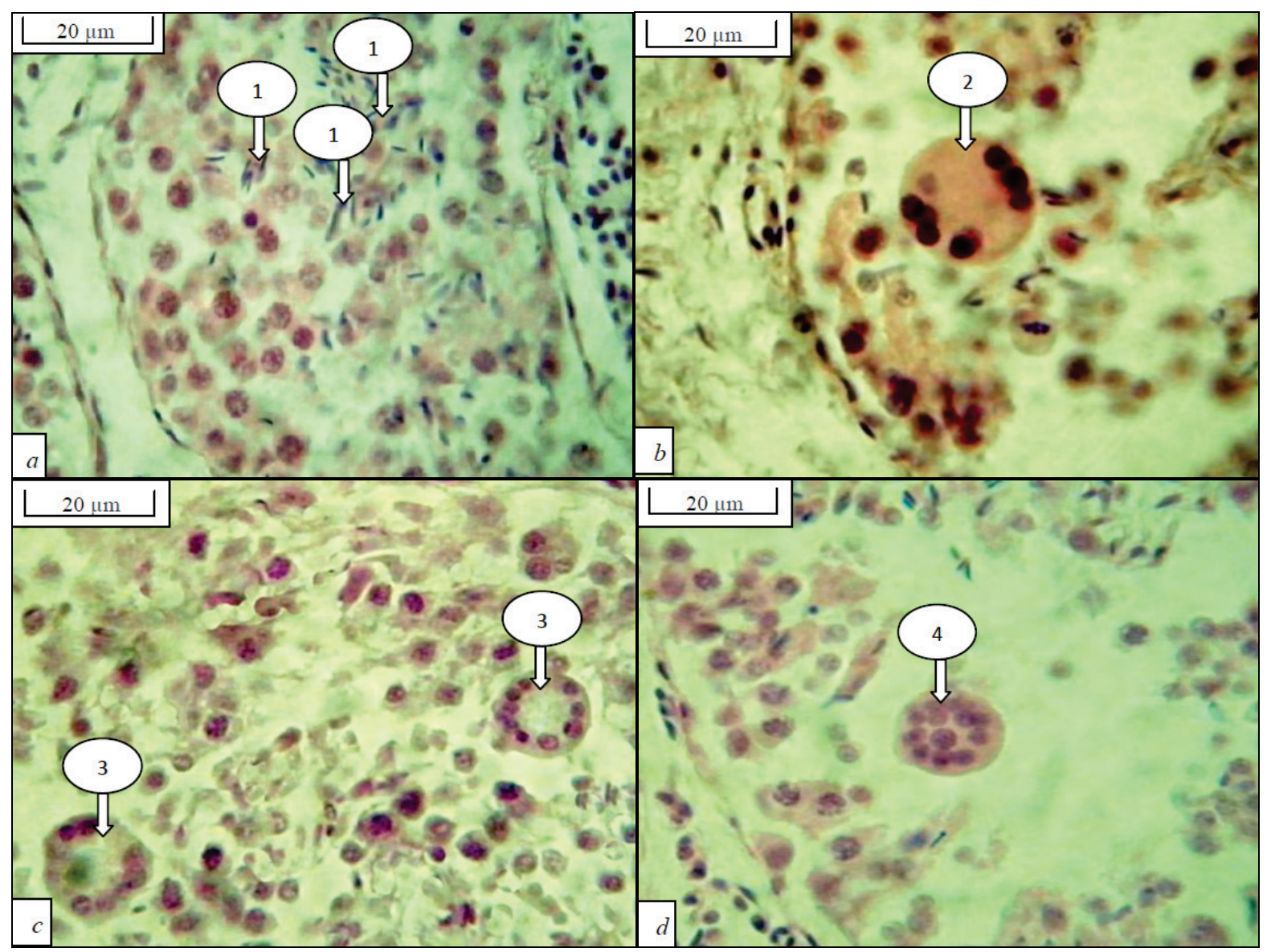

Fig. 3. Testicle of pig castrated immunologically: $a$-spermatids in the testicle $(1) ; b, c$-globular formation of spermatocytes in the ducti deferns of pig castrated immunologically $(2,3)$ - view from the side; $d$ - view from the top (4) (Bemer's hematoxylin, Hart's fuchselin (modified))

The authors report that immunological castration has an effect on the concentration of testosterone and weight of the testicles. These parameters, similarly to our study, were decreased. The scientists also indicate the fact that no long-term effects of immunological castration on the reproductive characteristics were determined (Lugar et al., 2017). Other authors also reported that Improvak vaccination affects the sizes of the reproductive organs - they were smaller in size as compared with non-vaccinated animals. The animals were also observed to have significant drop in the level of sex hormones (Brunius et al., 2011). These data are coherent with our results. After Improvak vaccination, testosterone concentration had decreased and remained at a low level for about six weeks. After around eight weeks after the castration, testosterone level began to increase (Wicksa et al., 2013).

Immunological castration leads to support of growth hormone at a certain level and loss of anabolic hormones: androgens, estrogens and insulin-like growth factor, but intensifies voluntary food consumption
(Bauer et al., 2009). The authors studied the consequences of early vaccination of pigs with Improvak. Similarly to the experiment we performed, they also observed impaired spermatogenesis and decrease in testosterone concentration. Leydig cells in the vaccinated pigs became pyknotic, and their number decreased. The authors conclude that early vaccination causes more serious damage to the structure and the functions of the testicles than the standard one (Einarsson et al., 2011). Early vaccination of pigs is also recommended to be used for the regulation of pigs' behaviour (Andersson et al., 2012).

Similarly to our case, Improvak immunization affected the quantity and morphology of interstitial Leydig cells, and spermatogenesis was also damaged to various extent - starting with impairment (decrease in the normal number of the layers of sex cell) to significant deficiency in sex cells, decrease in the amount of Sertoli cells (complete vanishing of cellular embryos) (Einarsson et al., 2009). Thus, an alternative to surgical castration is immunocastration against the gonadotropin releasing factor 
(GnRF). After complete immunization, we determined inhibition of the function of the testicles and hormonal status, which is coherent with the reports by other authors (Dunshea et al., 2013).

Two weeks after the secondary vaccination, we determined lower level of testosterone in the animals castrated by Improvak than in the surgical castrates. This fact may be explained by the report of the authors who determined that compared with non-castrated male pigs, the immunological castration decreases the serum concentration of luteinizing and folliclestimulating hormones, and also testosterone and inhibin, and causes severe atrophy of the testicles. After surgical castration, these concentrations increase (Han et al., 2017). The conclusion drawn states that the immunologic castration blocks directly the steroidogenesis in the testicles, reducing the synthesis of the gonadotropin releasing factor $(\mathrm{GnRH})$ in the hypothalamus, and then also the synthesis of luteinizing hormone of the hypophysis, and thereby impairs spermatogenesis (Han et al., 2014).

According to our surveys, Improvak immunization led to the situation when testosterone level in plasma decreased as significantly as in pigs castrated surgically and even more. Because of the drop in this level, growth of the testicles retards, and their relative weight, number of spermatozoa and their mobility decrease. The results we obtained correlate with the reports by the authors who also concluded that immunological castration is effective and quickly reduces testosterone level in blood serum, causing no chronic toxic impact, and may be broadly used in veterinary medicine, and maybe in human medicine in the future (Turkstra et al., 2011).

Thus, histological examinations confirm the fact that immunological castration is the method that temporarily inhibits spermatogenesis and production of steroids by the testicles. Our studies demonstrate that vaccination with Improvak causes significant atrophy of the testicles of pigs and decrease in their functional condition. We consider that immunological castration in pig husbandry may be used more widely so as to control secretion activity of the testicles.

\section{Conclusions}

Immunological castration affects the functional condition of the testicles. The parameter of the total testosterone in immunological castrates was lower than in the surgically castrated animals. The highest value of this parameter was determined in the male pigs that underwent no castration. Testosterone level after injection of Improvak was the lowest and gradually increased for 8 weeks, whereas in surgical castrates, it gradually decreased.

Specific cytoarchitectonic of spermatogenous generations indicates shifts in time and rates of mitotic cycle, which further determines the low degree of their differentiation with subsequent stop of the course of spermatogenesis stages. The low number of free second-order spermatocytes determines an equivalent amount of spermatids. Deficiency of spermatocytes occurs due to development of their specific conglomerations, within which the cellular differentiation is impossible. The restricting factor for spermatids' differentiation is decrease in testosterone level in the blood. The late stages of spermatogenesis are inhibited in immunologically castrate animals. The epithelium-spermatogenic layer was underdeveloped. Deficiency of Leydig cells was observed, indicating absence of the normal hormonal background and is confirmed by the results of the examination of testosterone level.

It is worth conducting further studies dealing with surveying of peculiarities of application of Improvak and optimizing the schemes of its application to pigs of various breeds, as well as analysis of its impact on biochemical parameters of meat products. Furthermore, a relevant issue is its interaction with medicinal preparations used in the conditions of industrial farms.

\section{References}

Aluwé, M., Tuyttens, F. A. M., \& Millet, S. (2015). Field experience with surgical castration with anaesthesia, analgesia, immunocastration and production of en tiremale pigs: Performance, carcass traits and boartaint prevalence. Animal, 9(3), 500-508.
Andersson, K., C. Brunius, C., Zamaratskaia, G., \& Lundström, K. (2012). Early vaccination with Improvac ${ }^{\circledR}$ : Effects on performance and behaviour of male pigs. Animal Getaccess, 6(1), 87-95.

Bauer, A., Lacom, M., \& Claus, R. (2009). Effects of two levels of feed al locationon IGF-I concentrations and metabolic parameters in GnRH-immunized boars. Journal of Animal Physiology and Animal Nutrition, 93(6), 744-753.

Baumgartner, J., Laistera, S., Koller, M., Pfützner, A., Grodzycki, M., Andrews, S., \& Schmoll, F. (2010). The behaviour of male fattening pigs followingei ther surgical castration or vaccination with a $\mathrm{GnRF}$ vaccine. Applied Animal Behaviour Science, 124, 28-34.

Bonneau, M., \& Weiler, U. (2019). Pros and cons of alternatives to piglet castration: Welfare, boar taint, and other meat quality traits. Animals, $9(11), 884$.

Bradford, J. R., \& Mellencamp, M. A. (2013). Immunological control of boar taint and aggressive behavior in male swine. Animal Frontiers, 3(4), 12-19.

Brunius, C., Zamaratskaia, G., Andersson, K., Chen, G., Norrby, M., Madej, A., \& Lundströma, K. (2011). Early immunocastration of male pigs with Improvac ${ }^{\circledR}$ Effect on boar taint, hormones and reproductive organs. Vaccine, 29(51), 9514 9520 .

Chen, M., Wang, J., Liu, N., Cui, W., Dong, W., Xing, B., \& Pan, C. (2019). Pig SOX9: Expression profiles of Sertoli cell (SCs) and a functional 18 bpindel affecting testis weight. Theriogenology, 138(15), 94-101.

Claus, R., Lacom, M., Danowski, K., Pearce, M. C., \& Bauer, A., (2007). Short-term endocrine and metabolic reactions before and after second immunization against GnRH in boars. Vaccine, 25(24), 4689-4696.

Dunshea, F. R., Allison, J. R. D., Bertram, M., Boler, D. D., Brossard, L., Campbell, R., Crane, J. P, Hennessy, D. P., Huber, L., de Lange, C., Ferguson, N., Matzat, P., McKeith, F., Moreas, P. J. U., Mullan, B. P., Noblet, J., Quiniou, N., \& Tokach, M. (2013). The effect of immunization against GnRF on nutrient requirements of male pigs: A review. Animal, 11(4), 643-649.

Einarsson, S., Andersson, K., Wallgrena, M., Lundström, K., \& Rodriguez-Martinez, H. (2009). Short- and long-term effects of immunization against gonadotropinreleasing hormone, using Improvac ${ }^{\mathrm{TM}}$, on sexual maturity, reproductive organs and sperm morphology in male pigs. Theriogenology, 71, 302-310.

Einarsson, S., Brunius, C., Wallgrena, M., Lundström, K., Andersson, K., Zamaratskaia, G., \& Rodriguez-Martinez, H. (2011). Effects of early vaccination with Improvac $^{\circledR}$ on the development and function of reproductive organs of male pigs. Animal Reproduction Science, 127, 50-55.

Fang, F., Li, H., Liu, Y., Zhang, Y., Tao, Y., Li, Y., Cao, H.,Wang, S., Wang, L., \& Zhang, X. (2010). Active immunization with recombinant $\mathrm{GnRH}$ fusion protein in boars reduces both testicular development and mRNA expression levels of GnRH receptor in pituitary. Animal Reproduction Science, 119, 275-281.

Gogić, M., Radović, Č., Čandek-Potokar, M., Petrović, M., Radojković, D., Parunović, N., \& Savić, R. (2019). Effect of immunocastration on sex glands of male Mangulica (Swallow-bellied Mangalitsa) pigs. Revista Brasileira de Zootecnia, $2019,48$.

Han, X., Cheng, W., Chen, Z., Du, X., Cao, X., \& Zeng, X. (2014). Active immunisation against pregnenolone reduces testicular steroidogenesis and GnRH synthesis in rabbits. Animal Reproduction Science, 145, 161-169.

Han, X., Zhou, Y., Zeng, Y., Sui, F., Liu, Y., Tan, Y., Cao, X., Du, X., Meng, F., \& Zeng, X. (2017). Effects of active immunization against GnRH versus surgical castration on hypothalamic-pituitary function in boars. Theriogenology, 97(15), 89-97.

Hilbe, M., Jaros, P., Ehrensperger, F., Zlinszky, K., Janett, F., Hässig, M., \& Thun, R. (2006). Histomorphological and immunohistochemical findings in testes, bulbourethral glands and brain of immunologically castrated male piglets. Schweizer Archiv für Tierheilkunde, 148, 599-608.

Kress, K., Millet, S., Labussière, É., Weiler, U., \& Stefanski, V. (2019). Sustainability of pork production with immunocastration in Europe. Sustainability, 11, 12.

Lugar, D. W., Rhoads, M. L., Clark-Deener, S. G., \& Callahan, S. R. (2017). Immunological castration temporarily reduces testis size and function without longterm effects on libido and sperm quality in boars. Animal, 11(4), 643-649.

Mitjana, O., Bonastre, C., Tejedor, T., Garza, L., Latorred, Á., Morenob, B., \& Falcetoa, V. (2020). Immuno-castration of female and male pigs with anti-gonadotrophin releasing hormone vaccine: Morphometric, histopathological and functional studies of the reproductive system. Animal Reproduction Science, 221, e106599.

Pasquale, J., Nannoni, E., Sardi, L., Rubini, G., Salvatore, R., Bartoli, L., Adinolfi, F., \& Martelli, G. (2019). Towards the abandonment of surgical castrationin pigs: How is immunocastration perceived by Italian consumers? Animals, 9(5), 198.

Škrlep, M., Batorek, N., Bonneau, M., Prevolnik, M., Kubale, V., \& Čandek-Potokar, M. (2012). Effect of immunocastration in group-housed commercial fattening pigs on reproductive organs, malodorous compounds, carcass and meat quality. Czech Journal of Animal Science, 57, 290-299.

Sladek, Z., Prudikova, M., Knoll, A., Kulich, P., Steinhauserova, I., \& Borilova, G. (2018). Effect of early immunocastration on testicular histology. Veterinama Medicina, 63, 18-27.

Turkstra, J. A., Staay, F. J., Stockhofe-Zurwieden, N., Woelders, H., Meloen, R. H., \& Schuurman, T. (2011). Pharmacological and toxicological assessment of a 
potential GnRH vaccine in young-adult male pigs. Vaccine, 29(21), 37913801

Tuyttensa, F. A. M., Vanhonacker, F., Verhille, B., Brabander, D., \& Verbeke, W. (2012). Pig producer at titude towards surgical castration of piglets without anaesthesia versus alternative strategies. Researchin Veterinary Science, 92(3), 524-530.

Wicks, N., Crouch, S., \& Pearl, C. A. (2013). Effects of Improvac and Bopriva on the testicular function of boars ten weeks after immunization. Animal Reproduction Science, 142(3-4), 149-159.

Yu, S., Zhang, P., Dong, W., Zeng, W., \& Pan, C. (2017). Identification of stem leydig cells derived from pig testicular interstitium. Stem Cells International, 2017, e2740272.
Yuna, J., Ollila, A., Valros, A., Larenza-Menzies, P., Heinonen, M., Oliviero, C., \& Peltoniemi, O. (2019). Behaviour al alterations in piglets after surgical castration: Effects of analgesia and naesthesia. Researchin Veterinary Science, 125, 36-42.

Zamaratskaia, G., \& Rasmussen, M. K. (2015). Immunocastration of Male Pigs Situation Today. Procedia Foodcience, 5, 324-327.

Zamaratskaia, G., Rydhmer, L., Andersson, K., Chen, G., Lowagie, S., Andersson, K., \& Lundström., K. (2007). Long-term effect of vaccination against gonadotropin-releasing hormone, using Improvac ${ }^{\mathrm{TM}}$, on hormonal profile and behaviour of male pigs. Animal Reproduction Science, 108, 37-48. 